J. Lake Sci. (湖泊科学), 2020, 32(5): 1519-1528

DOI 10. 18307/2020. 0523

(c) 2020 by Journal of Lake Sciences

\title{
基于越冬水鸟生境模拟的拟建鄱阳湖水利枢纽生态控制水位探讨
}

\author{
陈炼钢 ${ }^{1 * *}$, 陈黎明 ${ }^{1}$, 徐祎 ${ }^{1}$, 贾建伟 ${ }^{2}$, 栾震宇 ${ }^{1}$, 施 勇 $^{1}$, 金 秋 $^{1}$, 胡腾飞 ${ }^{1}$ \\ (1: 南京水利科学研究院水文水资源与水利工程科学国家重点实验室,南京 210029) \\ (2:长江水利委员会水文局,武汉 430010)
}

\begin{abstract}
摘 要: 长江及鄱阳湖水系上游水库群运用后鄱阳湖枯季水文节律出现新的变化, 为应对新的枯水情势, 鄱阳湖水利枢 纽作为一个选项被提出, 如何确定其适宜的调控水位才能维持鄱阳湖湿地生态系统健康是其中的重点与难点. 本文选择 鹤类、小天鹅、鸿雁等食植物块茎水鸟作为鄱阳湖湿地生态系统的指示物种, 基于 EFDC 水动力学模型和生境适宜度曲线 构建了鄱阳湖越冬水鸟生境数值模拟模型; 从食物资源与取食可及性两个方面, 分苦草 (Vallisneria natans) 生长期和水鸟 越冬期两个时段, 以水深作为关键生境因子, 对近 10 年鄱阳湖苦草及水鸟取食潜在生境面积变化进行了连续模拟; 揭示 了鄱阳湖苦草及水鸟取食潜在生境面积随水位的变化规律并构建了定量响应函数: 苦草潜在生境面积随水位呈单峰型 变化, 在星子站水位为 $14.8 \mathrm{~m}$ 时达到最大, 约为 $1703 \mathrm{~km}^{2}$; 越冬水鸟取食潜在生境面积随水位呈三段式变化, 最大和最小 面积分别约为 564 和 $476 \mathrm{~km}^{2}$, 相应星子站水位分别为 11.73 和 $9.56 \mathrm{~m}$. 在此基础上, 针对拟建的鄱阳湖水利枢纽工程, 基 于不同调度分期内生境保护目标的差异确定了符合天然水位波动特征的生态水位动态调控方案: 下闸蓄水期内水位宜 控制在 $16 \mathrm{~m}$ 以下, 后续根据越冬水鸟迁入情况逐步下降以增加取食生境面积, 在 12 月一次年 1 月的越冬水鸟数量峰值期 水位宜控制在 $12.5 \mathrm{~m}$ 以下, 后续根据来水情况逐步过渡至江湖连通期的自然状态. 成果从保护越冬水鸟食物资源与取食 可及性两个方面提出了鄱阳湖水利枢纽生态水位的动态调控阈值, 为江湖新水沙条件下鄱阳湖湿地生态系统保育提供 了量化依据.
\end{abstract}

关键词: 湿地; 越冬水鸟;沉水植被; 生境模拟; 生态需水; 鄱阳湖

\section{Ecological water level for proposed hydraulic construction locking Lake Poyang based up- on wintering waterfowls habitat modelling *}

CHEN Liangang $^{1 * *}$, CHEN Liming ${ }^{1}$, XU Yifan ${ }^{1}$, JIA Jianwei ${ }^{2}$, LUAN Zhenyu ${ }^{1}$, SHI Yong ${ }^{1}$, JIN Qiu $^{1}$ \& HU Tengfei ${ }^{1}$

(1: State Key Laboratory of Hydrology-Water Resources and Hydraulic Engineering, Nanjing Hydraulic Research Institute, Nanjing 210029, P.R.China)

(2: Bureau of Hydrology, Changjiang Water Resources Commission, Wuhan 430010, P.R.China)

Abstract: After the operation of the reservoirs in the upper basins of the Yangtze River and Lake Poyang, the hydrological rhythm in dry seasons of the Lake Poyang has changed. In order to ease the pressure from low water level in dry seasons, a hydraulic construction locking the outlet of Lake Poyang was suggested. The key point of this project is to determine the suitable control schemes on water level which could maintain a healthy wetland ecosystem. Cranes, Cygnets and Swan Geese feeding with winter buds of Vallisneria natans were selected as the indicator of Lake Poyang ecosystem, a numerical habitat model for wintering waterfowls was developed by integrating an EFDC hydrodynamic model and habitat suitability curves. The water depth was adopted as the key habitat factor, the habitats for the wintering waterfowls feeding in dry seasons and V. natans in wet seasons have been continuously simulated since September in 2008. The variation laws between water level at Xingzi Station and the potential habitat area of $V$. natans and

* 2019-09-23 收稿; 2020-01-16 收修改稿.

国家重点研发计划项目 (2017YFC0405300,2016YFC0402200) 和国家自然科学基金项目 (51679143, 51809180, $51909168)$ 联合资助.

** 通信作者;E-mail:lgchen81@ gmail.com. 
waterfowls feeding in Lake Poyang were revealed and the quantitative response functions were developed. The potential habitat area of $V$. natans gets the peak (around $1703 \mathrm{~km}^{2}$ ) when the water level reaches $14.8 \mathrm{~m}$. The three-stage quantitative response functions between potential habitat area and water level have been developed for wintering waterfowls feeding, the maximum and minimum areas are about 564 and $476 \mathrm{~km}^{2}$, respectively, and the corresponding water levels at Xingzi Station are 11.73 and $9.56 \mathrm{~m}$, respectively. For the proposed Lake Poyang hydraulic construction, a dynamic ecological water level control scheme as following is proposed: the water level should be controlled under $16 \mathrm{~m}$ during the refill period of Lake Poyang; then the water level would gradually decrease to increase the waterfowls feeding habitat areas; the maximum water level should be controlled below $12.5 \mathrm{~m}$ during December and January for the peak visiting of wintering waterfowls, and then gradually transits to natural state according to the inflow. The results could propose the ecological water control level for Lake Poyang hydraulic construction to protect the food resources and feeding accessibility of wintering waterfowls, and a quantitative basis for the conservation of Lake Poyang wetland ecosystem under new water-sand regime was provided.

Keywords: Wetlands; wintering waterfowls; submerged macrophyte; habitat simulation; ecological water demand; Lake Poyang

翻阳湖作为我国最大的淡水湖泊, 也是当前长江中下游仅存的两个大型通江湖泊之一, 与长江共同组 成了独特的江一湖复合生态系统; 周期性的洪枯水位节律变化及河湖相交替转换,造就了水陆兼有的独特生 境, 孕育了物种多样性丰富的湿地生态系统, 在全球候鸟保护及栖息地保护方面起着至关重要的作用, 是我 国唯一加人国际生命湖泊网的湖泊, 已列入《湿地公约》国际重要湿地名录, 在江西、长江流域、全国乃至全 球生态安全格局中具有十分重要的战略地位. 水位和水深是湖泊湿地生态系统的重要组分, 其变化节律直 接影响到湖区滩地的淹没和出露日期及持续时间, 对鸟类食物资源植物、鱼类、底栖动物等的产量、分布、物 种多样性、群落结构及演替产生直接影响 ${ }^{[1-4]}$. 鄱阳湖水位变化受流域 “五河” 和长江来水的双重影响, 长期 以来形成了固有的丰枯变化节律; 然而, 进人 21 世纪以来受长江及 “五河” 上游水库群运用等的影响, 鄱阳 湖枯水节律发生了明显变化: 枯水期提前、枯水历时延长, 最低枯水位更枯 ${ }^{[5-6]}$. 为了应对新的枯水情势, 江 西省提出兴建鄱阳湖水利枢纽工程按照 “调枯不控洪” 的方式保障枯水期的 “三生”用水. 该工程建议一提 出就引起国内外广泛关注, 其中湿地与越冬水鸟保护是焦点问题之一, 如何确定适宜的生态调控水位是重 点与难点.

目前已采用多种方法分析计算了鄱阳湖的生态水位,包括: 水文频率分析法 ${ }^{[7-9]}$ 、天然水位资料法 ${ }^{[10]}$ 、生 态水位系数法 ${ }^{[10]}$ 、湖泊形态法 ${ }^{[11]}$ 、生物空间需求法 ${ }^{[12]}$ 、情景分析法 ${ }^{[13]}$. 其中, 前 4 种方法主要基于物理因子 分析而生态学意义不明显; 后两种生态学意义较强, 通过生境遥感解译等获得若干水位下生境面积的变化 特征, 但由于遥感解译的数据点有限致使所得规律存在明显的不确定性. 相比于生境遥感解译数据点有限 的不足, 生境数值模拟通过长系列连续模拟可获得大量生境数据点, 从而提高其变化规律的确定性; 但是目 前还未见到通过生境数值模拟确定鄱阳湖生态水位的相关研究, 此外也未见到从候鸟食物资源和取食可及 性两方面考虑不同时段生境保护目标的差异来确定鄱阳湖生态水位动态调控过程的研究. 生境数值模拟将 物理生境因子条件和生物本身的需求结合起来, 模拟河湖水位流量和特定物种或群落适宜生境分布之间的 定量关系, 从而获得保护水生生物的生态水位和流量, 为河湖水资源合理开发利用提供依据; 被认为是生态 需水计算中较为可靠的方法, 一经提出便被各国广泛应用到工程实践中 ${ }^{[14]}$. 因此, 本文在构建鄱阳湖关键 物种生境数值模拟模型的基础上, 以水深为关键生境因子, 通过长系列的连续模拟, 从候鸟食物资源和取食 可及性两方面建立水位变化与重要生境面积之间的定量响应函数,并据此量化不同的调控水位对重要生境 的影响, 从而根据不同时段内生境保护目标的差异确定拟建鄱阳湖水利枢纽适宜的生态调控水位过程, 为 江湖新水沙条件下鄱阳湖湿地生态系统保育提供量化依据.

\section{1 重要生境及关键因子确定}

鄱阳湖是亚洲最大的候鸟越冬地, 有 “白鹤之乡” 和 “候鸟王国”之称, 是鹤类、鹳类、大铇、小天鹅等珍 禽和众多水禽的主要越冬栖息地:平均每年有 38.4 万余只候鸟在此越冬, 涉及种类 155 种, 其中 112 种为国 际湿地公约指定水鸟; 是世界上 $95 \%$ 的白鹤和 $75 \%$ 的东方白鹳等珍稀水禽种群的越冬场所 ${ }^{[15]}$, 也是迄今发 现的世界上最大的越冬鸿雁群体所在地, 数量达 3 万只以上 ${ }^{[16]}$. 如此多的候鸟与鄱阳湖丰富的食物资源密 
切相关, 根据食性的不同越冬候鸟分为 5 个主要取食集团: 食植物块茎集团、食苔草集团、食植物种子集团、 食无脊椎动物集团和食鱼集团 ${ }^{[17]}$. 其中, 食植物块茎的大多数鸟类列入《世界自然保护联盟》国际鸟类红皮 书名录和我国一、二级保护鸟类, 如白鹤、白枕鹤、小天鹅、大天鹅、鸿雁、赤颈鸭等 ${ }^{\left[{ }^{[6]}\right.}$; 尤以白鹤为典型, 因为 白鹤是除了鄱阳湖以外几乎没有其他可替代适宜栖息地的物种 ${ }^{[18]}$. 因此以白鹤为代表的食植物块茎鸟类 可作为鄱阳湖越冬候鸟的指示物种, 其生境的保育对于维护鄱阳湖湿地生态系统健康至关重要. 当前长江 流域沉水植被分布范围日趋狭窄, 导致了以块茎为食的小天鹅、鸿雁和鹤类集中分布在鄱阳湖和安徽的几 个湖泊; 而安徽沿江湖群面积相对较小且湿地环境正在迅速退化, 鄱阳湖将是这些水鸟最后的家园. 然而 2013 年第 2 次鄱阳湖科学考察却发现沉水植物分布面积缩减了 $37.72 \%{ }^{[19]}$, 鄱阳湖块茎资源主要来自沉水 植物优势种苦草 (Vallisneria natans). 因此, 越冬水鸟食物资源——苦草的保育对鄱阳湖湿地生态系统保护 至关重要;一旦丧失,鹤类、小天鹅、鸿雁等大批水鸟将可能灭绝.

食物资源、水深、人类干扰、湖床底质等都会影响水鸟对栖息地的选择,研究发现苦草冬芽密度和水深 的交互作用能够解释 $75 \%$ 的白鹤受食区变化 ${ }^{[20]}$. 每年的 3 月中下旬 -10 月底是鄱阳湖苦草生长期,其中 7 月中旬之前为营养生长期,之后为繁殖生长期. 鹤类等越冬水鸟从 10 月开始飞抵鄱阳湖, 到次年 4 月初基 本离开, 其中 11 月数量急剧增加、 12 月和次年 1 月达到峰值, 然后逐渐迁飞 ${ }^{[16]}$. 苦草的生长期和候鸟的越 冬期在鄱阳湖形成一个完美的交替接力, 这也是 $95 \%$ 以上的白鹤选择鄱阳湖越冬的原因之一. 水生生物生 境模拟的主要因子包括水深、流速、底质、含沙量、水温等, 关键生境因子的遴选是生境模拟准确与否的关 键 ${ }^{[14]}$. 苦草的生长受水深、光照强度、透明度、基质、营养盐等多种环境因子的影响 ${ }^{[21]}$, 其中水深是最重要的 影响因子. 研究表明苦草的株数、叶片长度、叶片厚度、地下块茎——冬芽密度等随水深变化显著 ${ }^{[22-24]}$. 长时 间水淹或干旱均能导致沉水植物种群密度和生物量大大降低,进而影响到种群的更新和恢复 ${ }^{[25]}$, 如 1998 年 大洪水过后苦草大面积死亡并持续影响到次年的生物量 ${ }^{[26]}, 2003$ 年后长期的低枯水位导致苦草等沉水植 物群落面积大幅缩减 ${ }^{[19]}$. 冬季水深是影响水鸟取食可及性的决定性因子: 水位过高则水鸟不能正常取食苦 草等沉水植物的块茎; 水位过低则苦草等水鸟喜好的食物易枯死, 且泥滩表面基质干燥也妨碍水鸟正常取 食 ${ }^{[17,20]}$. 因此, 本文选择水深作为苦草生长期和候鸟越冬期的关键生境因子开展模拟及评估.

\section{2 模型与方法}

以鹤类、小天鹅、鸿雁等食植物块茎水鸟作为鄱阳湖越冬水鸟指示物种, 从食物资源与取食可及性两方 面, 分苦草生长期和候鸟越冬期两个时段对其生境进行评价,包括物理生境因子时空分布模拟和生境适宜 度评价两部分, 量化水位变化对越冬水鸟潜在生境面积的影响规律, 为鄱阳湖水利枢纽生态调控水位的确 定提供依据.

\section{1 物理生境因子模拟}

鄱阳湖越冬水鸟物理生境因子时空变化模拟基于环境流体动力学模型 EFDC( Environmental Fluid Dynamics Code), 该模型包括水动力、温热、水质和泥沙等模块. EFDC 是美国国家环保署 USEPA 法定推荐的水 系统模拟模型之一 ${ }^{[27]}$, 被广泛用于模拟河流、河口、湖泊、水库、湿地系统以及自近岸到陆架的海域一维、二 维和三维流场、物质输运 (包括温、盐、粘性和非粘性泥沙的输运)、生态过程及淡水人流, 能同时考虑风、浪、 潮、径流的影响, 并可以设置水工建筑物 ${ }^{[28]}$. 本次物理生境因子模拟主要用到 EFDC 的水动力模块, 其水动 力学方程采用垂向静压假定, 在水平方向上采用曲线正交坐标, 垂直方向上采用 $\sigma$ 坐标变换, 沿重力方向分 层求解三维紊动粘性方程, 主要模型方程如下 ${ }^{[29]}$.

(1) 连续方程:

$$
\frac{\partial(m \zeta)}{\partial t}+\frac{\partial\left(m_{y} H u\right)}{\partial x}+\frac{\partial\left(m_{x} H v\right)}{\partial y}+\frac{\partial(m w)}{\partial z}=S_{h}
$$

(2) 动量方程:

$$
\begin{gathered}
\frac{\partial(m H u)}{\partial t}+\frac{\partial\left(m_{y} H u u\right)}{\partial x}+\frac{\partial\left(m_{x} H v u\right)}{\partial y}+\frac{\partial(m w u)}{\partial z}-\left(m f+v \frac{\partial m_{y}}{\partial x}-u \frac{\partial m_{x}}{\partial y}\right) H v= \\
-m_{y} H \frac{\partial(g \zeta+p)}{\partial x}-m_{y}\left(\frac{\partial h}{\partial x}-z \frac{\partial H}{\partial x}\right) \frac{\partial p}{\partial z}+\frac{\partial}{\partial x}\left(\frac{m_{y}}{m_{x}} H A_{H} \frac{\partial u}{\partial x}\right)+
\end{gathered}
$$




$$
\begin{gathered}
\frac{\partial}{\partial y}\left(\frac{m_{x}}{m_{y}} H A_{H} \frac{\partial u}{\partial y}\right)+\frac{\partial}{\partial z}\left(\frac{m}{H} A_{v} \frac{\partial u}{\partial z}\right)-m c_{p} D_{p} u \sqrt{u^{2}+v^{2}}+S_{u} \\
\frac{\partial(m H v)}{\partial t}+\frac{\partial\left(m_{y} H u v\right)}{\partial x}+\frac{\partial\left(m_{x} H v v\right)}{\partial y}+\frac{\partial(m w v)}{\partial z}+\left(m f+v \frac{\partial m_{y}}{\partial x}-u \frac{\partial m_{x}}{\partial y}\right) H u= \\
-m_{x} H \frac{\partial(g \zeta+p)}{\partial y}-m_{x}\left(\frac{\partial h}{\partial y}-z \frac{\partial H}{\partial y}\right) \frac{\partial p}{\partial z}+\frac{\partial}{\partial x}\left(\frac{m_{y}}{m_{x}} H A_{H} \frac{\partial v}{\partial x}\right)+ \\
\frac{\partial}{\partial y}\left(\frac{m_{x}}{m_{y}} H A_{H} \frac{\partial v}{\partial y}\right)+\frac{\partial}{\partial z}\left(\frac{m}{H} A_{v} \frac{\partial v}{\partial z}\right)-m c_{p} D_{p} u \sqrt{u^{2}+v^{2}}+S_{v} \\
\frac{\partial p}{\partial z}=-g H \frac{\rho-\rho_{0}}{\rho_{0}}
\end{gathered}
$$

式中, $u$ 和 $v$ 为曲线正交坐标 $x$ 和 $y$ 方向上的水平速度分量 $(\mathrm{m} / \mathrm{s}), w$ 为 $\sigma$ 坐标 $z$ 方向上的垂直速度分量 $(\mathrm{m} /$ $\mathrm{s}) ; t$ 为时间 $(\mathrm{s}) ; m_{x}$ 和 $m_{y}$ 为水平坐标变换因子 $(\mathrm{m}), m=m_{x} m_{y} ; p$ 为压力 $(\mathrm{Pa}) ; H$ 为总水头 $(\mathrm{m}), H=h+\zeta, h$ 为 床底高程 $(\mathrm{m}), \zeta$ 为水面水深 $(\mathrm{m}) ; f$ 为科氏力系数 $\left(\mathrm{s}^{-1}\right) ; A_{H}$ 为水平紊动扩散系数 $\left(\mathrm{m}^{2} / \mathrm{s}\right), A_{v}$ 为垂向涡粘系数 $\left(\mathrm{m}^{2} / \mathrm{s}\right) ; S_{h}$ 为质量源汇项 $\left(\mathrm{m}^{3} / \mathrm{s}\right), S_{u}$ 和 $S_{v}$ 分别为 $x$ 和 $y$ 方向上的动量源汇项 $\left(\mathrm{m}^{2} / \mathrm{s}^{2}\right) ; c_{p}$ 为植被阻力系数, $D_{p}$ 为植被占比系数; $g$ 为重力加速度 $\left(9.81 \mathrm{~m} / \mathrm{s}^{2}\right) ; \rho$ 为水密度 $\left(\mathrm{kg} / \mathrm{m}^{3}\right), \rho_{0}$ 为水的标准密度 $\left(1000 \mathrm{~kg} / \mathrm{m}^{3}\right)$.

鄱阳湖人湖水系较多, 模型上边界设为五河尾问人流, 其中竷江西支、北支、中支和南支依据外洲站流 量和各分支断面面积进行概化分配, 抚河采用李家渡站流量, 信江东大河、西大河依据梅港站流量和各分支 断面面积进行概化分配, 绕河采用渡峰坑和石镇街站流量叠加, 修水采用虬津站和万家埠站流量叠加, 下边 界采用湖口水位 (位置如图 1 所示). 鄱阳湖丰枯水期水位及湖面面积变化显著: 枯水期呈现明显的 “河

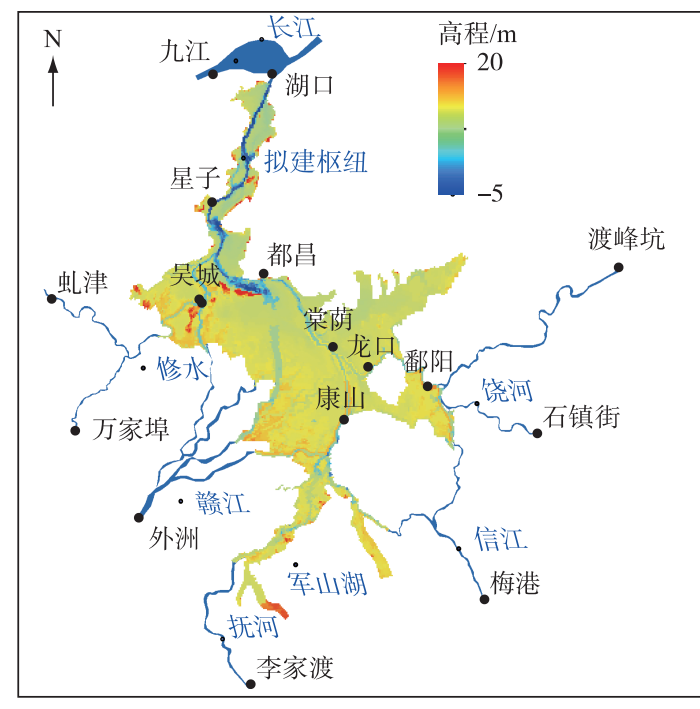

图 1 鄱阳湖水系概化及地形

Fig.1 River network and bathymetry in Lake Poyang 相”, 水流只在河道深槽中流动, 大部分滩地显露; 丰水期呈现明显的“湖相”, 湖面宽广, 水流趋于静 止. 因此, 为了能够精确地模拟鄱阳湖年内河湖相 的交替变化过程和反映计算域的特征,采用曲线正 交贴体网格对计算域进行剖分, 网格剖分尽量沿主 河槽或堤防, 精确地概化出河道、滩地、岛屿等边界 的过度衔接, 使水流方向尽可能真实地体现流动状 态, 并对湖区内主槽中网格进行加密处理. 最终得 到水平网格 14110 个, 范围覆盖了“五河”下游尾问 地区和整个丰水期时的湖面, 且将已与主湖分隔的 军山湖剥离出计算域, 共计 $3292 \mathrm{~km}^{2}$, 如图 1 所示, 绝大部分网格尺寸在 $200 \sim 500 \mathrm{~m}$ 之间, 湖区内主槽 网格小至 $150 \mathrm{~m}$ 左右, 部分滩地网格大至 $1000 \mathrm{~m}$ 左右. 由于本文主要模拟水深的变化, 因此垂向上 设置为 1 层以提高模型计算效率. 湖床高程采用鄱 阳湖 2010 年 $1: 1$ 万实测水下地形资料 (国家 85 高 程基准) 进行插值, 插值后的地形如图 1 所示, 可见 模型所用网格清晰地描述了深槽、滩地、岛屿等地 形的变化.

2008 年 9 月 28 日三峡水库开始 $175 \mathrm{~m}$ 正常蓄水位的试验性蓄水,因此模型从 2008 年 9 月开始滚动计 算直至 2017 年 12 月. EFDC 水动力模块的关键参数为床面粗䊁高度, 经率定后取值在 $0.023 \sim 0.03 \mathrm{~m}$ 之间. 为反映 “五河七口” 以下 $20 \%$ 左右未控区间产流对湖区水量平衡的影响, 采用预估一校正模式进行两次模 拟: 先仅基于 “五河七口” 实测流量模拟获得湖口出流计算值, 将其与实测湖口流量的差值作为全湖的未控

(1) 与吴淞基面高差为 $-0.09 \mathrm{~m}$,与国家 85 高程基面高差为 $-1.929 \mathrm{~m}$,下同. 
区间水量;然后将估算的未控区间水量按照同期五河来水量比 例叠加到边界人流上进行校正计算. 模型对鄱阳湖区星子站、 吴城 (修水) 站、吴城 (赣江) 站、棠荫站、鄱阳站、龙口站、康山 站和都昌站 8 个站的水位进行了验证,绝大部分时段水位误差 控制在 $0.15 \mathrm{~m}$ 以内; 鄱阳湖代表性水位控制站星子站水位模 拟值与实测值的对比如图 2 所示 ${ }^{\circledR}$. 可见, 基于 EFDC 构建的湖 区水动力模型能很好地模拟鄱阳湖水位的时空分布变化.

\section{2 生境适宜度评价}

生境适宜度评价采用全球广为应用的适宜度曲线法 ${ }^{[30]}$. 适宜度曲线以生境因子的数值为横坐标, 以目标物种对此生 境因子的适宜度为纵坐标, 建立目标物种对单个生境因子的

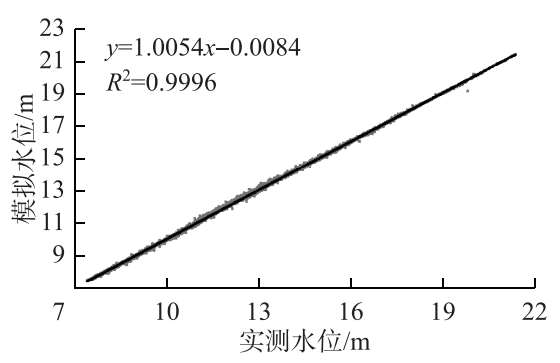

图 2 星子站水位验证情况

Fig.2 Model verification for water level at Xingzi Station 偏好与生境因子之间关系的连续曲线,能定量描述物理生境特 征与物种在该条件下的生存质量. 用 0 和 1 之间的数值定义目标物种对单因子的偏好, 曲线的峰值代表生 物对该因子的最适宜范围. 针对影响苦草生长的关键生境因子水深, 相关研究表明其生长的适宜水深为 $1 \sim$ $2 \mathrm{~m}$, 水深超过 $2 \mathrm{~m}$ 后由于水下光照过小导致生物量及冬芽形成数量迅速下降, 水深低于 $1 \mathrm{~m}$ 光照过强造成 光损伤, 也会抑制苦草的生长 ${ }^{[23,31-36]}$; 据此制定苦草生长的水深适宜度曲线 (图 3a). 相关调查发现鹤类、鸿 雁、东方白鹳的受食水深都在 $50 \mathrm{~cm}$ 以内, 小天鹅受食水深略大, 可到 $80 \mathrm{~cm}$, 彻斛类受食水深略浅, 为 40 $\mathrm{cm}$; 其中鹤类、小天鹅、东方白鹳的最适受食区水深分别在 $20 \sim 30 、 15 \sim 40 、 30 \mathrm{~cm}$ 左右 ${ }^{[16,37]}$. 综合后拟定 $0 \sim$ $60 \mathrm{~cm}$ 浅水区作为越冬水鸟的受食区、20 40 cm 作为其适宜受食水深, 据此制定鄱阳湖越冬水鸟取食的水 深适宜度曲线 (图 3b).

根据各网格单元水深及其适宜度指数采用加权可用面积法 ${ }^{[38]}$ 计算潜在适宜生境面积:

$$
W U A=\sum_{i=1}^{n} S I_{i} A_{i}
$$

式中, $W U A$ 为加权可用生境面积 $\left(\mathrm{km}^{2}\right), A_{i}$ 和 $S I_{i}$ 为第 $i$ 个网格单元的面积 $\left(\mathrm{km}^{2}\right)$ 和生境适宜度.
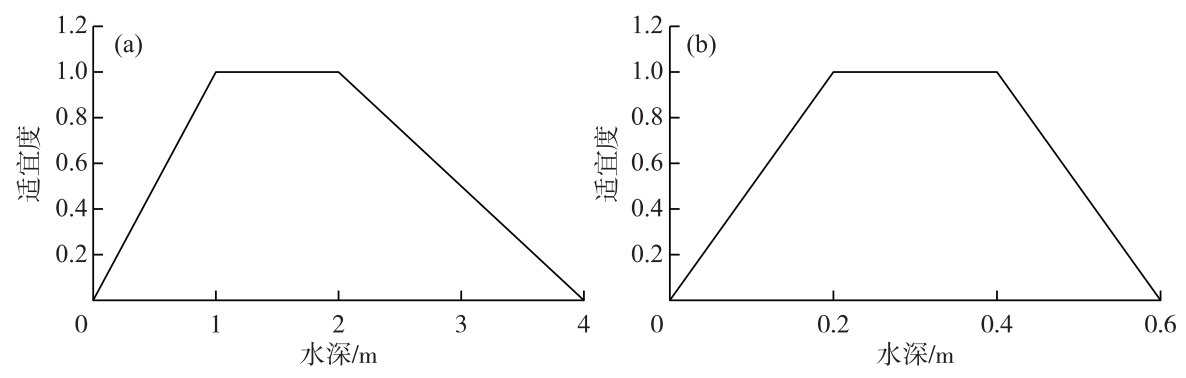

图 3 苦草 $(a)$ 和水鸟取食 $(b)$ 水深适宜度曲线

Fig.3 Habitat suitablity curves for Vallisneria natans (a) and waterfowls feeding (b)

\section{3 结果与讨论}

\section{1 生境面积一水位的定量响应规律}

以苦草的生长期 3 月中旬一 10 月下旬为分析时段, 根据星子站实测水位和模拟计算的苦草潜在适宜生 境面积相关图 (图 4a), 采用门限回归法建立鄱阳湖苦草潜在生境面积对水位变化的定量响应关系, 见公式 (6). 以越冬水鸟数量峰值时段 12 月和 1 月为分析时段, 根据星子站实测水位和模拟计算的水鸟取食潜在 适宜生境面积相关图 (图 4b), 采用门限回归法建立水鸟取食潜在生境面积对水位变化的定量响应关系, 见 公式(7). 


$$
\begin{gathered}
W U A 1=\left\{\begin{array}{lc}
-0.240162 Z^{6}+16.11619 Z^{5}-446.8749 Z^{4}+6551.890 Z^{3}- \\
53533.22 Z^{2}+230994.3 Z-410472 & Z \leqslant 14.80 \\
0.339957 Z^{6}-36.74921 Z^{5}+1642.9420 Z^{4}-38871.134 Z^{3}+ & Z>14.80 \\
513185.54 Z^{2}-3584151.4 Z+10347462 & Z \leqslant 9.56
\end{array}\right. \\
\text { WUA2 }= \begin{cases}-14.139 Z+614.23 & 9.56<Z<11.73 \\
40.362 Z+90.44 & Z \geqslant 11.73 \\
-116.32 Z+1928.6 & Z\end{cases}
\end{gathered}
$$

式中, $W U A 1$ 为苦草潜在适宜生境面积 $\left(\mathrm{km}^{2}\right), W U A 2$ 为水鸟取食潜在适宜生境面积 $\left(\mathrm{km}^{2}\right), Z$ 为星子站水位 $(\mathrm{m})$. 从图 4a 可见, 苦草潜在生境面积随水位呈单峰型变化, 在星子站水位为 $14.8 \mathrm{~m}$ 时达到最大, 约为 1703 $\mathrm{km}^{2}$; 当水位低于或高于这一临界点时, 潜在生境面积均下降, 高水区比低水区下降速率更快, 说明洪水比枯 水对苦草的损害更大: 当星子水位低于 $9 \mathrm{~m}$ 后, 潜在生境稳定在 $700 \mathrm{~km}^{2}$ 左右; 而当星子水位涨至 $19 \mathrm{~m}$ 时, 枯 草潜在生境面积仅剩约 $190 \mathrm{~km}^{2}$, 超过 $20 \mathrm{~m}$ 后全湖苦草生境几乎全部丧失;2016 年和 2017 年连续两年鄱阳 湖遭遇大洪水,最高洪水位分别为 21.36 和 $20.87 \mathrm{~m}$, 洪水过后主湖区和碟形湖均未发现沉水植物活体, 且 2018 年尚未恢复 ${ }^{[19]}$. 从图 4b 可见,越冬水鸟取食潜在生境面积随水位呈三段式变化,在星子站水位为 $11.73 \mathrm{~m}$ 时达到最大, 为 $564 \mathrm{~km}^{2}$; 随着水位的升高, 取食潜在生境面积急剧下降; 而随着水位的降低, 取食潜 在生境面积先下降,然后基本稳定并略有抬升; 在星子站水位为 $9.56 \mathrm{~m}$ 时达到最小, 为 $476 \mathrm{~km}^{2}$, 随后基本稳 定在 $500 \mathrm{~km}^{2}$ 左右; 这一规律的形成是由于鄱阳湖区存在大量的蝶形子湖且湖底平坦, 当主槽水位下降到某 一阈值后蝶形子湖与主槽分离, 湖区水面面积趋于稳定, 并随着水位的进一步下降更多的水域变为浅水区.
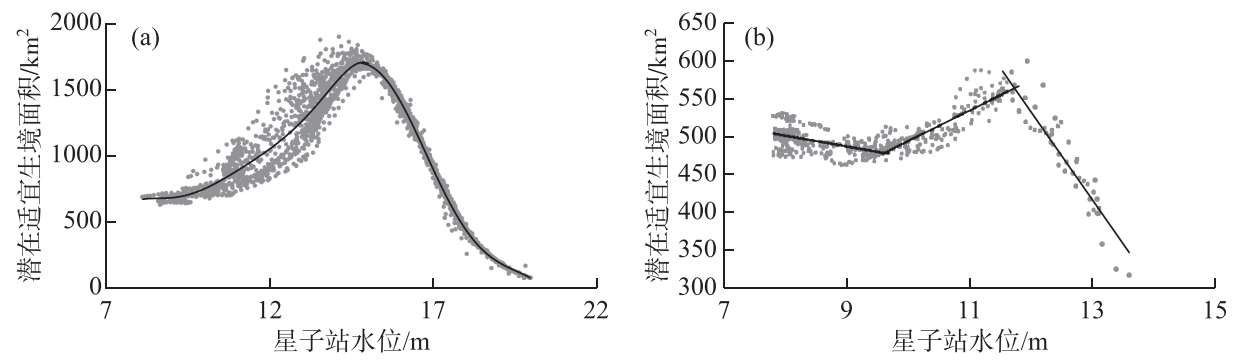

图 4 苦草 $(\mathrm{a})$ 和水鸟取食 $(\mathrm{b})$ 潜在生境面积随水位变化

Fig.4 Habitat area vers water level for Vallisneria natans (a) and waterfowls feeding ( b)

\section{2 拟建鄱阳湖枢纽生态控制水位}

拟建的鄱阳湖水利枢纽选择在鄱阳湖人江水道的屏峰山与长岭山之间建闸, 上距星子县城约 $12 \mathrm{~km}$,下 至鄱阳湖人长江口约 $27 \mathrm{~km}$ (位置见图 1). 论证中的鄱阳湖大闸水位调控按照 “调枯不控洪” 的方式分为 5 个时段: 江湖连通期 ( 4 月 1 日- 8 月 31 日)、下闸蓄水期( 9 月 1 日 -20 日)、长江上游水库蓄水调节期( 9 月 21 日- 10 月 31 日)、补偿调节期( 11 月 1 日一次年 2 月 28 日)、低枯水位调控期( 3 月 1 日一 31 日 $)^{[15]}$. 前 3 个调度期基本覆盖了苦草的生长期, 其中下闸蓄水期和长江上游水库蓄水调节期处于苦草的繁殖生长期 内, 对冬芽的生长至关重要; 后 3 个调度期基本覆盖候鸟越冬期, 其中补偿调节期内候鸟密集迁人和迁离, 并在 12 月一次年 1 月达到数量峰值, 为候鸟越冬的关键时段.

为科学论证鄱阳湖水利枢纽的可行性, 江西省政府邀请国内权威机构的专家从江湖关系、泥沙冲淤、防 洪、水质、湿地与候鸟、水生动物等方面开展 6 项专题研究和论证. 其中 “湿地与候鸟”专题指出 “要使鄱阳湖 水利枢纽工程不对鄱阳湖湿地和水鸟造成灾难性影响, 至少需要保持目前 $80 \%$ 以上的草洲、泥沙滩和浅水 水域作为水鸟栖息地”. 按照这一判定标准, 采用 3.1 节建立的生境面积与水位的函数关系, 量化星子站不 同水位下鄱阳湖苦草及越冬水鸟潜在生境面积的变化, 然后根据不同调度时段内生境保护目标的差异确定 鄱阳湖生态水位的动态调控过程: 鄱阳湖大闸下闸蓄水期内生境保护目标为苦草, 水位不宜超过 $16 \mathrm{~m}$, 苦草 潜在生境面积与最大值相比偏小幅度可控制在 $20 \%$ 以内 (空间分布见图 $5 \mathrm{a}$ ) ; 长江上游水库蓄水调节期内 
生境保护目标以苦草为主兼顾越冬水鸟,宜将水位控制在 14.0 15.5 m 区间, 苦草潜在生境面积与最大值相 比偏小幅度可控制在 $10 \%$ 以内 (空间分布见图 $5 \mathrm{~b}$ ), 同时可为少数飞抵的候鸟保留近 $25 \%$ 以上的受食生境 (空间分布见图 6a); 补偿调节期内生境保护目标为越冬水鸟, 此间越冬水鸟大量迁人并达到数量峰值, 可根 据候鸟飞抵的情况从前一调度期水位逐步下降以增加取食生境面积, 在 12 月一次年 1 月的越冬候鸟数量峰 值期内水位不宜超过 $12.5 \mathrm{~m}$, 此时越冬水鸟潜在取食生境面积与最大值相比偏小幅度可控制在 $20 \%$ 以内 (空间分布见图 6b); 低枯水位调控期内候鸟已大量迁离, 同时苦草逐步进人萌发期, 两者对生境的需求都 大幅降低,可延续前一调度期的控制水位并逐步过渡到自然状态.
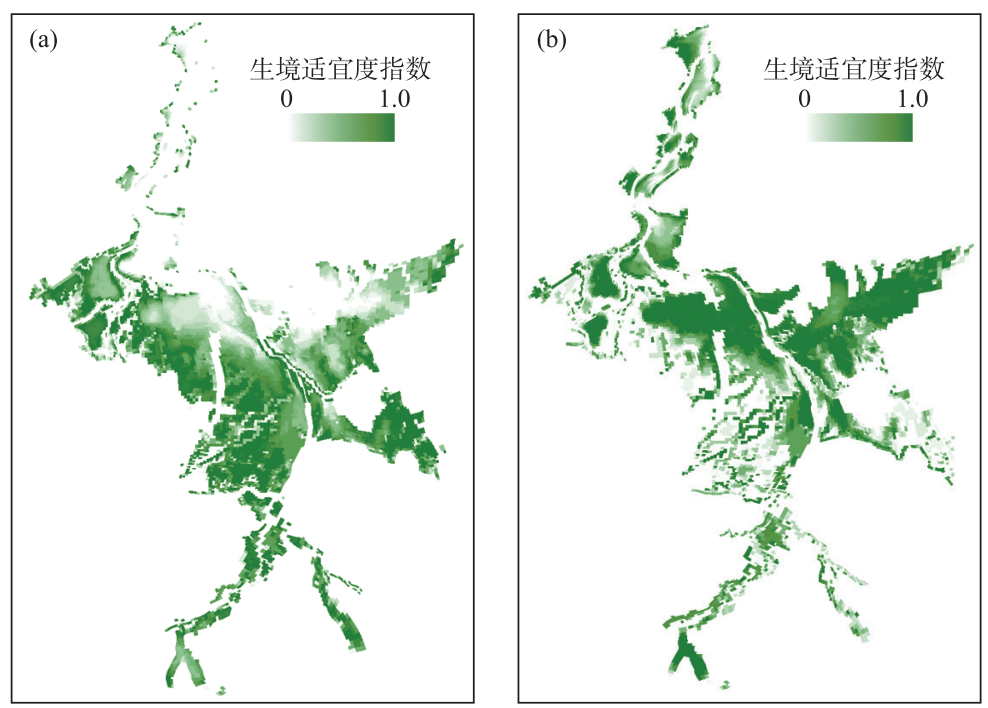

图 5 苦草潜在生境分布: (a) 星子站水位 $16 \mathrm{~m}$; (b) 星子站水位 $14 \mathrm{~m}$

Fig.5 Habitat distribution for Vallisneria natans: (a) $Z_{\text {xingzi }}=16 \mathrm{~m}$; (b) $Z_{\text {xingzi }}=14 \mathrm{~m}$
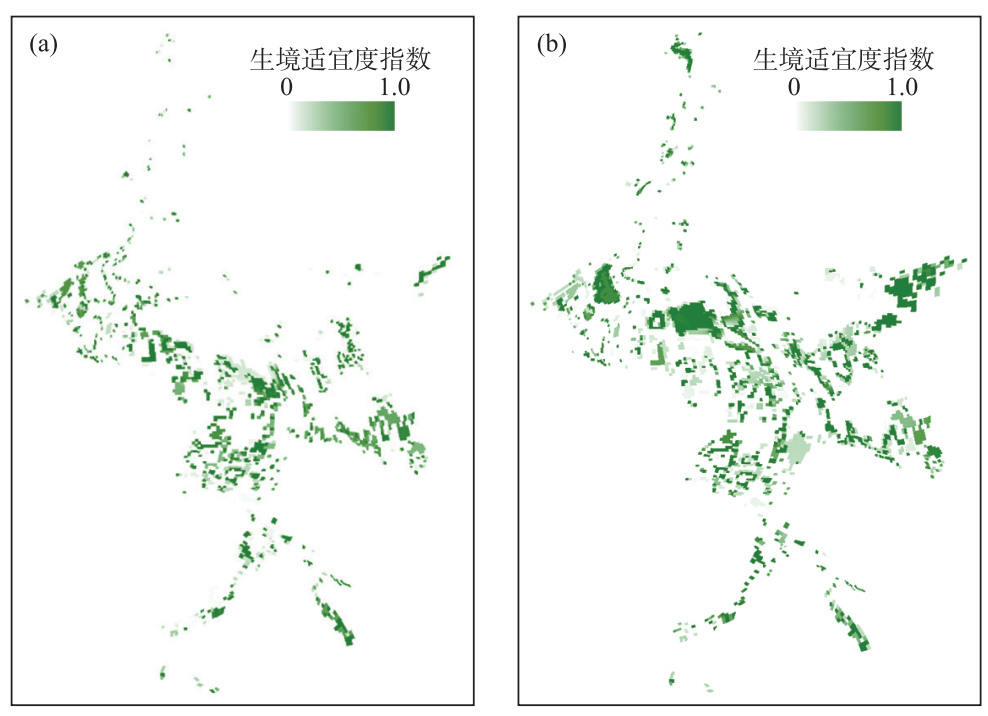

图 6 越冬水鸟取食潜在生境分布: (a) 星子站水位 $14 \mathrm{~m}$; (b) 星子站水位 $12.5 \mathrm{~m}$

Fig.6 Habitat area distribution for waterfowls feeding: (a) $Z_{\text {xingzi }}=14 \mathrm{~m}$; (b) $Z_{\text {xingzi }}=12.5 \mathrm{~m}$ 
基于三峡运用前 1953-2002 年星子站月平均水位序列,统计出的鄱阳湖水利枢纽调度期内各月 5\%高 水位、50\%平水位、95\%枯水位见表 $1^{[8]}$. 本文得出的生态调控水位与此对比可见: 9 月蓄水期内最高控制水 位 $16 \mathrm{~m}$ 略低于当月多年平水位; 10 月长江上游水库蓄水调节期内最低控制水位 $14 \mathrm{~m}$ 稍低于当月多年平水 位; 12 月一次年 1 月越冬候鸟数量峰值期内最高控制水位 $12.5 \mathrm{~m}$ 稍高于 12 月多年高水位; 一定程度上说明 本文得出的生态调控水位的动态过程符合水位的天然波动特征. 扰动对维持生态系统的弹性及物种多样性 等具有重要意义, 然而按此控制建闸后鄱阳湖秋、冬季水位变幅收窄至 $3.5 \mathrm{~m}$ 左右, 虽可有效保障越冬水鸟 潜在生境面积, 但其变化趋于稳定且扰动幅度将显著减小, 是否会对湿地生态系统产生不可逆的不利影响 有待更深人的研究.

\section{表 1 三峡工程运用前星子站水位特征值}

Tab.1 Characteristic value of water level at Xingzi Station before the operation of Three Gorges Project

\begin{tabular}{ccccccccc}
\hline \multirow{2}{*}{ 频率 } & \multicolumn{7}{c}{ 水位特征值/m } \\
\cline { 2 - 9 } & 9 月 & 10 月 & 11 月 & 12 月 & 1 月 & 2 月 & 3 月 \\
\hline $5 \%$ & 19.30 & 17.57 & 15.03 & 12.20 & 11.28 & 11.67 & 13.59 \\
$50 \%$ & 16.11 & 14.67 & 12.20 & 9.71 & 8.84 & 9.69 & 11.14 \\
$95 \%$ & 12.94 & 11.78 & 9.79 & 8.04 & 7.55 & 7.83 & 8.82 \\
\hline
\end{tabular}

\section{4 结论}

以鹤类、小天鹅、鸿雁等食植物块茎水鸟作为鄱阳湖越冬候鸟指示物种, 基于 EFDC 水动力学模型和生 境适宜度曲线, 构建了鄱阳湖越冬水鸟生境数值模拟模型; 以水深作为关键生境因子, 对 2008 年 9 月三峡水 库 $175 \mathrm{~m}$ 试验性蓄水后鄱阳湖重要生境变化进行了连续模拟.

1) 从鸟类食物资源与取食可及性 2 个方面, 分苦草生长期和候鸟越冬期 2 个时段, 建立了星子站水位 对苦草及水鸟取食潜在生境面积的定量影响函数. 苦草潜在生境面积随水位呈单峰型变化; 在星子站水位 为 $14.8 \mathrm{~m}$ 时达到最大, 约为 $1703 \mathrm{~km}^{2}$; 越冬水鸟取食潜在生境面积随水位呈三段式变化, 在星子站水位为 11.73 和 $9.56 \mathrm{~m}$ 时分别达到最大和最小, 约为 564 和 $476 \mathrm{~km}^{2}$.

2) 针对拟建的鄱阳湖水利枢纽工程, 分析计算了星子站不同水位下苦草及越冬水鸟取食潜在生境面积 的变化, 并据此基于不同调度分期内生境保护目标的差异确定了符合天然水位波动特征的生态水位动态调 控方案:下闸蓄水期内水位不宜超过 $16 \mathrm{~m}$, 后续根据越冬候鸟迁人情况逐步下降, 在 12 月一次年 1 月的越冬 候鸟数量峰值期内水位不宜超过 $12.5 \mathrm{~m}$, 后续根据来水情况逐步过渡至江湖连通期的自然状态.

本文提出的生态水位调控方案主要满足鹤类、小天鹅、鸿赝等食植物块茎水鸟的生境需求, 下阶段应进 一步研究其他物种生境对水深的需求, 从而制定物种覆盖面更广的生态控制水位, 为鄱阳湖湿地生态系统 保育提供更为全面深人的科学依据.

\section{5 参考文献}

[ 1 ] Baschuk MS, Koper N, Wrubleski DA et al. Effects of water depth, cover and food resources on habitat use of marsh birds and waterfowl in boreal wetlands of Manitoba, Canada. Waterbirds, 2012, 35(1) : 44-55. DOI: 10.1675/063.035.0105.

[ 2 ] González-Gajardo A, Sepúlveda PV, Schlatter R. Waterbird assemblages and habitat characteristics in wetlands: Influence of temporal variability on species-habitat relationships. Waterbirds, 2009, 32(2) : 225-233. DOI: 10.1675/063.032.0203.

[ 3 ] van Geest GJ, Coops H, Roijackers RMM et al. Succession of aquatic vegetation driven by reduced water-level fluctuations in floodplain lakes. Journal of Applied Ecology, 2005, 42(2) : 251-260. DOI: 10.1111/j.1365-2664.2005.00995.x.

[ 4 ] Hu ZP, Ge G, Liu CL et al. Structure of Poyang lake wetland plants ecosystem and influence of lake water level for the structure. Resources and Environment in the Yangtze Basin, 2010, 19(6): 597-605. [胡振鹏, 葛刚, 刘成林等. 鄱阳湖 湿地植物生态系统结构及湖水位对其影响研究. 长江流域资源与环境, 2010, 19(6): 597-605.]

[ 5 ] Min Q, Zhan LS. Characteristics of low-water level changes in Lake Poyang during 1952-2011. J Lake Sci, 2012, 24( 5) : 
675-678. DOI: 10.18307/2012.0505. [闵骞, 占腊生. 1952- 2011 年鄱阳湖枯水变化分析. 湖泊科学, 2012,24 (5) : 675-678.]

[ 6 ] Zhou YK, Bai XL, Ning LX. Research on the variation and mutation of water level in Poyang lake during 1970-2015. Journal of Henan University: Natural Science, 2018, 48(2) : 151-159. [周云凯, 白秀玲, 宁立新. 1970-2015 年鄱阳 湖水位变化特征及其突变分析. 河南大学学报: 自然科学版, 2018, 48(2): 151-159.]

[ 7 ] Liu JY, Zhang Q, Gu XH et al. Study on ecological-level of the Poyang lake based on variable bandwidth kernel density estimation. Acta Scientiarum Naturalium Universitatis Sunyatseni, 2015, 54(3): 151-157. [刘剑宇, 张强, 顾西辉等. 基于变带宽核密度估计的鄱阳湖生态水位研究. 中山大学学报:自然科学版, 2015, 54(3): 151-157.]

[ 8 ] Chen J, Duan M, Wu PJ et al. Study on the ecological water level of Poyang Lake with different time scales. Jiangxi Hydraulic Science \& Technology, 2018, 44(3) : 160-163. [陈江, 段明, 吴培军等. 不同时间尺度的鄱阳湖生态水位研 究. 江西水利科技, 2018, 44(3): 160-163.]

[ 9 ] He J, Xia ZQ, Huang F et al. Lake ecological water level calculation based on wet, normal and dry years. Water Resources and Power, 2017, 35(5):33-36. [贺金, 夏自强, 黄峰等. 基于丰平枯水年的湖泊生态水位计算. 水电能源科学, $2017,35(5): 33-36$.

[10] Huang XM. The research on Poyang lake wetland ecological water requirement [Dissertation]. Nanchang: Nanchang University, 2011. [黄小敏. 鄱阳湖湿地生态需水研究 [学位论文]. 南昌: 南昌大学, 2011.]

[11] Liu HY, Gui FL. Study on lowest ecological water requirement for lakes of taking in \& sending out waters: A case study in Poyang Lake Wetland. Journal of Nanchang Institute of Technology, 2011, 30(6) : 69-72. [刘惠英, 桂发亮. 吞吐型湖 泊湿地最低生态需水研究——鄱阳湖湿地为例. 南昌工程学院学报, 2011, 30(6): 69-72.]

[12] Liu HY, Wang YW, Guan XZ. Suitable ecological water level in Poyang Lake wetland: A case study in Xingzi Hydrological Station. Journal of Nanchang Institute of Technology, 2012, 31(3): 46-50. [刘惠英, 王永文, 关兴中. 鄱阳湖湿地 适宜生态需水位研究——星子站水位为例. 南昌工程学院学报, 2012, 31(3): 46-50.]

[13] Qi SH, Liao FQ. A study on the scheme of water level regulation of the Poyang Lake hydraulic project. Acta Geographica Sinica, 2013, 68(1) : 118-126. [齐述华, 廖富强. 鄱阳湖水利枢纽工程水位调控方案的探讨. 地理学报, 2013, 68 (1) : 118-126.]

[14] Yi YJ, Zhang SH. Review of aquatic species habitat simulation method and modelling. Scientia Sinica: Technologica, 2019, 49(4) : 363-377. [易雨君, 张尚弘. 水生生物栖息地模拟方法及模型综述. 中国科学: 技术科学, 2019, 49 (4) : 363-377.]

[15] Luo W. Study on eco-hydrological process and regulation countermeasures in typical wetland of Poyang Lake under changing environment [Dissertation]. Wuhan: Wuhan University, 2014. [罗蔚. 变化环境下鄱阳湖典型湿地生态水文过程 及其调控对策研究 [学位论文]. 武汉: 武汉大学, 2014.]

[16] Tang GH. Study on evolution, protection and management of Poyang lake's wetland [Dissertation]. Nanchang: Nanchang University, 2017. [唐国华. 鄱阳湖湿地演变、保护及管理研究 [学位论文]. 南昌: 南昌大学, 2017.]

[17] Jia YF. Impact of water level fluctuation on Siberian crane and other wintering waterbirds in Poyang lake [Dissertation]. Beijing: Beijing Forestry University, 2013. [贾亦飞. 水位波动对鄱阳湖越冬白鹤及其他水鸟的影响研究 [ 学位论 文]. 北京: 北京林业大学, 2013.]

[18] Barter M, Lei G, Lei C eds. Waterbird survey of the middle and lower Yangtze River floodplain in February 2005. Beijing: World Wildlife Fund-China and Chinese Forestry Publishing House, 2005.

[19] Hu ZP, Lin YR. Analysis of evolution process and driving factors for aquatic vegetations of Poyang lake in 30 years. Resources and Environment in the Yangtze Basin, 2019, 28(8): 1947-1955. [胡振鹏, 林玉茹. 鄱阳湖水生植被 30 年演 变及其驱动因素分析. 长江流域资源与环境, 2019, 28(8): 1947-1955.]

[20] Chen B. Study on population change of wintering waterfowl and suitability evaluation of white crane habitat under different water level scenarios in Poyang Lake [Dissertation]. Nanjing: Nanjing Normal University, 2014. [陈冰. 鄱阳湖不同水 位情景下越冬水鸟种群数量变化及白鹤生境适宜性评价研究 [学位论文]. 南京: 南京师范大学, 2014.]

[21] Wang H, Pang Y, Liu SB et al. Research progress on influencing of environmental factors on the growth of submersed macrophytes. Acta Ecologica Sinica, 2008, 28(8):3958-3968. [王华, 逢勇, 刘申宝等. 沉水植物生长影响因子研究进 展. 生态学报, 2008, 28(8): 3958-3968.]

[22] Gu YF, Wang J, Wang J et al. Morphological response and growth strategy of the submerged macrophyte Vallisneria natans 
under different water depths. J Lake Sci, 2017, 29(3) : 654-661. DOI: 10.18307/2017.0314. [ 顾燕飞, 王俊, 王洁等. 不同水深条件下沉水植物苦草 (Vallisneria natans) 的形态响应和生长策略. 湖泊科学, 2017, 29(3) : 654-661.]

[23] Yuan LY, Li SC, Li W. The effects of water level fluctuation on the winter bud formation of submerged macrophyte Vallisneria spinulosa. Journal of Jiangxi Normal University: Natural Sciences Edition, 2013, 37(4) : 355-358. [袁龙义, 李守 淳, 李伟. 水深变化对刺苦草冬芽形成的影响研究. 江西师范大学学报: 自然科学版, 2013, 37(4) : 355-358.]

[24] Yuan LY, Li W. Effects of water depths and substrate types on the distribution in winter buds of Vallisneria spinulosa in Poyang lake. Journal of Yangtze University: Natural Science Edition, 2008, 5(1):55-58, 100. [袁龙义, 李伟. 水深和 基质对鄱阳湖刺苦草冬芽分布的影响. 长江大学学报：自然科学版, 2008, 5(1): 55-58, 100.]

[25] MacEk P, Rejmánková E, Houdková K. The effect of long-term submergence on functional properties of Eleocharis cellulosa Torr. Aquatic Botany, 2006, 84(3) : 251-258. DOI: 10.1016/j.aquabot.2005.11.003.

[26] Cui XH, Zhong Y, Li W et al. The effect of catastrophic flood on biomass and density of three dominant aquatic plant species in the Poyang lake. Acta Hydrobiologica Sinica, 2000, 24(4): 322-325. [崔心红, 钟扬, 李伟等. 特大洪水对鄱 阳湖水生植物三个优势种的影响. 水生生物学报, 2000, 24(4) : 322-325.]

[27] Li YP, Gong R, Paul · Craig eds. Numerical simulation and prediction on water environment. Beijing: Science Press, 2019. [李一平, 龚然, 保罗-克雷格. 地表水环境数值模拟与预测 : EFDC 建模技术及案例实训. 北京: 科学出版 社, 2019.]

[28] Ji ZG ed. Hydrodynamics and water quality modeling rivers, lakes, and estuaries. Hoboken: Jonh Wiley and Sons, Inc., 2017.

[29] Craig PM. Theoretical \& computational aspects of the environmental fluid dynamics code-plus ( EFDC+). Dynamic Solutions-International, LLC, Edmonds, WA, 2017.

[30] Yi YJ, Cheng X, Zhou J. Research progress in habitat suitability assessment methods. Ecology and Environmental Sciences, 2013, 22 (5) : 887-893. [易雨君, 程曦, 周静. 栖息地适宜度评价方法研究进展. 生态环境学报, 2013, 22 (5) : 887-893.]

[31] Barzen J, Engels M, Burnham J et al. Potential impact of a water control structure on the abundance and distribution of wintering waterbirds at Poyang Lake. Wisconsin, USA: International Crane Foundation, 2009.

[32] Li QS, Huang Q, Li YJ et al. Effects of water depth on growth of submerged macrophytes Vallisneria natans and Myriophyllum spicatum. J Lake Sci, 2019, 31(4) : 1045-1054. DOI: 10.18307/2019.0404. [李启升, 黄强, 李永吉等. 水深对 沉水植物苦草 (Vallisneria natans) 和穗花狐尾藻 (Myriophyllum spicatum) 生长的影响. 湖泊科学, 2019, 31 (4) : 1045-1054.]

[33] Yang X, Sun SY, Bai X et al. Influences of water depth gradient on photosynthetic fluorescence characteristics of Vallisneria natans. J Lake Sci, 2014, 26(6) : 879-886. DOI: 10.18307/2014.0610. [杨金金, 孙淑雲, 柏祥等. 水深梯度对苦 草 (Vallisneria natans) 光合苂光特性的影响. 湖泊科学, 2014, 26(6) : 879-886.]

[34] Fu H, Yuan GX, Cao T et al. Clonal growth and foraging behavior of a submerged macrophyte Vallisneria natans in response to water depth gradient. J Lake Sci, 2012, 24(5) : 705-711. DOI: 10.18307/2012.0510. [符辉, 袁桂香, 曹特 等. 水深梯度对苦草 (Vallisneria natans) 克隆生长与受食行为的影响. 湖泊科学, 2012, 24(5) : 705-711.]

[35] Yao ZD. Effects of light on the growth of Vallisneria natans under changing hydrological conditions in Poyang Lake [ Dissertation]. Nanchang: Nanchang Institute of Technology, 2018. [姚志东. 鄱阳湖变化水文条件下光照对苦草生长的影 响 [学位论文]. 南昌: 南昌工程学院, 2018.]

[36] Zhang SJ. The influence of Vallisneria natans growth under water gradient/light intensity [ Dissertation]. Nanchang: Jiangxi Normal University, 2016. [张素娟. 水深/光照对苦草生长的影响研究 [学位论文]. 南昌: 江西师范大 学, 2016.]

[37] Xia SX, Yu XB, Fan N. The wintering habitats of migrant birds and their relationship with water level in Poyang lake, China. Resources Science, 2010, 32(11) : 2072-2078. [夏少霞, 于秀波, 范娜. 鄱阳湖越冬季候鸟栖息地面积与水 位变化的关系. 资源科学, 2010, 32(11) : 2072-2078.]

[38] Zhang WG, Huang Q, Jiang XH. Study on instream ecological flow based on physical habitat simulation. Advances in Water Science, 2008, 19(2): 192-197. [张文鸽, 黄强, 蒋晓辉. 基于物理栖息地模拟的河道内生态流量研究. 水科学进 展, 2008, 19(2) : 192-197.] 